\title{
Shelter seeking behaviour of healthy donkeys and mules in a hot climate
}

\author{
Emily Haddy ${ }^{a}$, Faith Burden ${ }^{b} \&$ Leanne Proops ${ }^{a}$
}

a Centre for Comparative and Evolutionary Psychology, Department of Psychology, University of Portsmouth, Portsmouth PO1 2DY, UK.

${ }^{\mathrm{b}}$ The Donkey Sanctuary, Sidmouth, Devon, EX10 0NU, UK.

Corresponding Authors: Emily Haddy \& Leanne Proops, Centre for Comparative and Evolutionary Psychology, Department of Psychology, University of Portsmouth, Portsmouth, PO1 2DY, UK. Email: emily.haddy@port.ac.uk, leanne.proops@port.ac.uk 


\begin{abstract}
Exposure to environmental factors such as high temperatures and solar radiation levels present a welfare concern for many domestic equids. Understanding how these factors influence the shelter use of healthy equids can inform welfare guidelines. While there is research assessing horses' responses to hot, dry climates, the use of shelter by healthy, semi-free ranging donkeys and mules has not been assessed. We observed the shelter seeking behaviour (SSB) of 109 donkeys and 21 mules, with free access to constructed shelters, across two locations during summer in Southern Spain. The location of each equid, either utilising a constructed shelter, outside unprotected or using natural protection, was observed. This was recorded alongside measures of environmental conditions including temperature, lux, wind speed and level of insect harassment. Equids were observed using some form of protection from the elements in $39 \%$ of observations. Increasing temperatures and lux levels predicted increased shelter use whereas temperature and wind speed were key predictors of outside protection use. Compared to donkeys, shelter seeking by mules was more sensitive to changes in a number of environmental factors including lux, temperature and level of insect harassment. Results indicate that rates of protection use are quite high in these conditions and that shelters are utilised under particular environmental conditions: high temperatures, high lux levels and increased wind speeds, indicating they are likely to confer a significant welfare advantage.
\end{abstract}

Keywords: Shelter Use, Shelter Seeking, Equine welfare, Animal Welfare, Protection from the elements. 


\section{Introduction}

For animals, high ambient temperatures, solar radiation and humidity can lead to heat stress (Silanikove, 2000). The range of ambient temperatures in which an animal can maintain its core temperature without using additional energy to that needed for maintenance, is termed the thermal neutral zone (TNZ) (Curtis, 1983). The effect of heat in the environment becomes physiologically challenging to an animal when the ambient temperature surpasses their TNZ (Holcomb, 2017). Once the temperature has exceeded the TNZ, both physiological and behavioural mechanisms can to be used to dissipate the extra heat load in order to keep the core temperature stable (Holcomb, 2017). This can be achieved by increasing respiration rate and sweating to aid evaporative cooling, peripheral vasodilation, increase in drinking and shade seeking (Holcomb et al., 2013; Morgan, 1998; Morgan et al., 1997). Available space, feeding and access to water will therefore affect an animal's ability to regulate its own heat dissipation. It has been suggested that solar radiation can often contribute more to heat load than ambient temperature (Silanikove, 2000), thus, one important method of mitigating heat stress, from solar radiation in particular, is for an animal to seek shade.

In horses the upper critical temperature (UCT) has been estimated to be between 20 and 30 degrees Celsius (Morgan, 1998) and is influenced by environmental factors such as solar radiation, humidity, wind speed and precipitation (Autio et al., 2006). Studies investigating the shade use of horses in high temperatures have found that respiration rate, amount of sweating, skin temperature and rectal temperature of horses exposed to mean afternoon temperatures of 30.6 degrees without access to shade, were higher than counterparts with access to shade (Holcomb et al., 2013). Domestic and captive wild horses use shade at above chance levels when exposed to ambient temperatures above $25^{\circ} \mathrm{C}$ (Holcomb et al., 2014; Holcomb and Stull, 2016). Notably, shade use is often not highest at the hottest times of day, but occurs before peak temperatures, when solar radiation is at its highest. However, even when provided with shelters, some horses do not use them and there appear to be significant individual differences in patterns of shelter use (Cymbaluk \& Christison, 1990; Hartmann et al., 2015; Honstein \& Monty, 1977). Climatic factors also affect the degree of insect challenge faced by equids, with high temperatures and sun, combined with low wind speeds, yielding the highest levels of harassment, and significantly affecting their movement and shelter use (Keiper and Berger, 1982; Rubenstein and Hohmann, 1989). In a population of island dwelling feral horses, bays and beaches (locations where insect harassment behaviours were lowest), were used most during the summer. This was especially evident during peak temperatures (Keiper and Berger, 1982) and overall habitat use reflected a pattern of refuge-seeking from biting flies (Powell et al., 2006). Although horses use natural refuges, evidence of artificial shelter use to avoid insect harassment has been mixed. Some studies have found an increase in shelter use when insect harassment levels were high and a reduction in insect harassment behaviours when inside a shelter (Hartmann et al., 2015; Snoeks et al., 2015), while others have observed no difference between insect harassment behaviour rate in shaded and unshaded areas, or a trend towards increased insect harassment behaviour in the shade (Holcomb et al., 2014, 2013). It is likely that differences in the proximity of environmental features such as standing water, mud or nearby agriculture will influence the prevalence of insects in exposed and shaded areas, producing these differing results. 
There are currently very few studies assessing environmental effects on donkey and mule behaviour and physiology. Standard donkeys have been shown to seek shelter more readily than horses in cold, wet weather and do not grow a significant winter coat in a temperate climate, suggesting they are less adapted to colder climates than many horse breeds (Osthaus et al., 2017; Proops et al., 2019). However, the thermal neutral zone for donkeys has not been documented. A study of donkeys in Nigeria suggests that the hot-dry season is physiologically stressful, with the most thermally challenging period falling between $11 \mathrm{am}$ and $4 \mathrm{pm}$ (Ayo et al., 2008). Increasing evaporative cooling by increasing respiration rate and sweating have been hypothesised as the main mechanisms used by donkeys to release heat on exposure to high temperatures, therefore increased respiration rate has been suggested as a good indicator of heat stress in donkeys (Ayo et al., 2014; Zakari et al., 2018). A study of shade provision showed that the heart rates, respiration rates and rectal temperatures of packing donkeys in Nigeria provided with shade were significantly lower than their unshaded counterparts (Minka and Ayo, 2007). Donkeys provided with shade also carried their loads significantly faster and lost significantly less weight by the end of the packing season than unshaded donkeys (Minka and Ayo, 2007). Lying behaviour was also observed more in shaded donkeys, this was hypothesised as a behavioural method of heat regulation resulting from the cooler soil temperature underneath the shades. However, it is important to note that these studies were carried out on working animals who are unlikely to be in the best health and welfare states and so may not reflect donkeys' natural ability to cope with hot temperatures. There are currently no studies that have explored SSB in healthy mules and donkeys in high temperatures with free access to shelter.

Over $85 \%$ of the world's equids are found in low and middle income countries (LMIC's) where they are most commonly used as working animals (Burn et al., 2010a). Working equids are used in a variety of industries, from small scale subsistence agriculture to large scale tourism and construction industries (Swann, 2006). They are exposed to a range of environmental conditions including extremes of temperature and humidity. With equids being recorded working (pulling carts and carrying loads) in temperatures of $44^{\circ} \mathrm{C}$, heat stress and dehydration have been identified as major threats to the welfare of working equids in LMIC's, reducing productivity and in extreme cases causing equid mortality (Dey et al., 2010; Pritchard et al., 2008, 2006). It is therefore important to understand the natural shelter seeking behaviour of healthy donkeys, horses and mules in hot climates, to provide a benchmark with which to ensure the welfare needs of domestic equids are being met. This study aimed to investigate behavioural patterns of shelter use in healthy mules and donkeys, located in a hot, semi-arid environment, with free access to shelter across a range of environmental conditions. Identifying the environmental factors influencing shelter use in this population can be used to inform understanding of shelter requirements for equids working in hot climates. 


\section{Materials and Methods}

\subsection{Study Animals and Locations}

A total of 130 equids (109 donkeys and 21 mules) were observed across two locations in Southern Spain, 74 were male and 56 female, mean donkey age was $16.5 \pm 8.1( \pm S D)$ years, mean mule age $29.3 \pm 5$ years. Donkey breeds included 1 Martina Franca donkey, 8 Sardinian donkeys and the remaining were standard donkeys. The breed history of the mules was unknown. Individuals included in the study were healthy, semi-free-ranging equids with access to shelter. Inclusion criteria were that shelter must be freely available to individuals and all animals were regularly monitored by veterinary surgeons employed by the The Donkey Sanctuary. 36 fully clipped animals ( 4 mules and 32 donkeys) were included but observations were not taken for foals under 1 year of age.

49 equids (41 donkeys and 8 mules) were studied at El Refugio del Burrito's public sanctuary in Fuente de Piedra, Andalucía, Spain. Equids were housed in 9 groups of between 3 and 14 individuals, with access to a roofed brick shelter and outdoor paddock area (Figure 1a). Shelters had one mainly open side acting as an entrance/exit and a window in one other side, shelters had capacity for all equids in the small social groups and the majority of equids in the larger groups. There was little natural shade but the walls of the shelter buildings provided outside shade. 81 equids ( 68 donkeys and 13 mules) were studied at El Refugio del Burrito's Doña Rosa sanctuary near Fregenal in Extremadura, Spain. Equids were housed in 8 groups of between 3 and 18 individuals with access to barns for shelter (Figure 1b.) and large outdoor paddock areas. Some groups also had access to a covered porch area with troughs for feeding. As well as the outside shade provided by the constructed shelters, some natural cover was available in the form of trees and vegetation. Water was provided inside and outside shelters at both of these sites and food was provided outside the shelter with the exception of fresh bedding material which was often eaten.

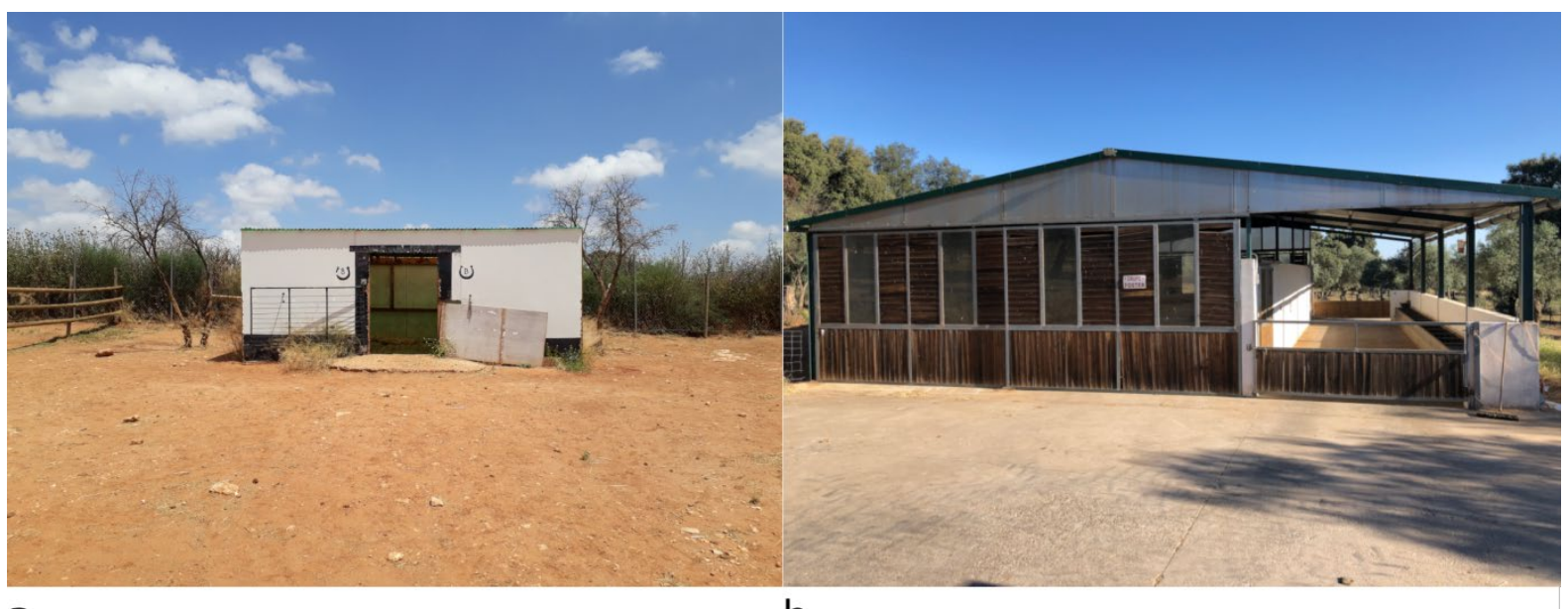

a.

b.

Fig. 1. Typical shelters provided at each of the study sites. a. Fuente de Piedra, Andalucía, Spain b. Doña Rosa, Extremadura, Spain. 


\subsection{Climate}

The climates in the study areas of Spain are classified as a mixture of hot-summer Mediterranean and cold semi-arid according to Köppen climate classification (Kottek et al., 2006). Hot-summer Mediterranean is characterised by dry hot summers and mild winters with most precipitation seen in autumn. Cold semi-arid climate is present in some of the driest areas of Extremadura and is characterised by the dry season extending beyond the end of summer resulting in less dense vegetation. Temperatures are highest in the months of July and August where Extremadura and inland Andalucía experience temperatures routinely exceeding $40^{\circ} \mathrm{C}$. Mean historic temperatures for the study period were $30^{\circ} \mathrm{C}$ with $21 \mathrm{~mm}$ of precipitation for the Extremadura region and $27^{\circ} \mathrm{C}$ with $13 \mathrm{~mm}$ of precipitation for inland Andalucía (Agencia Estatal de Meteorologia, Instituto de Meteorologia Portugal, 2011).

\subsection{Procedure}

The study was carried out between the $25^{\text {th }}$ of May and the $13^{\text {th }}$ of July 2018. Data was collected at one study site at a time, for between two and three weeks at each site. Groups at each study site were observed multiple times a day, with a minimum of one hour between observations and a maximum number of seven observations of each animal per day. The groups were cycled randomly (where possible within the sanctuary care routines) throughout the day. Data was collected between the hours of 8am and $4.15 \mathrm{pm}$.

For each group the time at the start of the observation was recorded, followed by the weather conditions at the location, including outside temperature, wind speed, lux level and precipitation. Lux levels were recorded using a Sinometer MS 6612 digital lux meter, measurements were taken with the meter held level and facing upwards. Temperature and wind speed were measured using a Skywatch Meteos Handheld Wind Meter Anemometer. The areas that the group currently had access to were recorded, for example shelter, hardstanding and earth. To minimise disturbing the equids' natural behaviours, the location of all equids outside was recorded from outside the enclosure where possible, in addition to their current activity (feeding on grass, feeding on a provided food, standing, resting recumbent, locomotion, other or unknown/disturbed). Any signs of potential heat stress were recorded, including sweating, visibly high respiration rate or open nostrils. If subjects were outside, whether they were in the sun, the shade or if it was overcast was recorded. It was determined to be overcast when no clearly defined shadows were visible. Whether it was dry, they were standing in the rain, or they had found natural protection such as trees was recorded. It was noted whether it was calm (less than $5 \mathrm{~m} / \mathrm{s}$ wind speed), they were standing in the wind, or they were protected. Subsequently the researcher entered the shelters and recorded the location and activity of those equids inside the shelter (trying to minimise disturbance). If an equid was disturbed by the researcher before observation of their activity the 'unknown' option in the coding was used. The temperature, lux and wind speed inside the shelter were measured using the same instruments used to measure the outside temperature. 
Finally, insect density and harassment measures were recorded. 3 equids that were standing in the sun were chosen, 3 inside the shelter and 3 standing in the shade (if there were individuals in all of these possible locations). Where possible the three equids included individuals with different coat colours, one light, one medium and one dark. To prevent subject selection bias, the closest individual encountered, of the correct coat colour, in the correct position was used. A timer was started and all behavioural measures of insect nuisance: head shaking, tail swishing, foot stamping, body biting and skin flickering (panniculus reflex) were recorded for one minute. This was followed by a point count of flies on one of the equid's sides, from the researcher's position. The number of behavioural measures of insect nuisance and the number of flies observed across the three individuals in each location were averaged and recorded as group measures for the observation session. When no animals were found in a location, no insect density measures could be recorded for that location but when fewer than three individuals were present in a location, data were recorded for as many animals as possible. The time at the end of the group observation was recorded.

Demographic information on all equids included in the study was recorded, including species, sex, age, breed, coat colour and whether or not the equid had been clipped. Not all group members were present for every observation and some individuals moved between groups during the study period but all equids kept their unique subject number. In total 2735 observations were made, with an average of $14 \pm 4$ observations per subject.

\subsection{Statistical Analysis}

In order to ascertain which environmental factors had an influence on the equids' shelter seeking behaviour, generalised linear mixed models (GLMM) with a binomial logit function were undertaken using RStudio, version 1.0.143 (RStudio Team, 2015) with the Ime4 package and number of iterations set to maximum.

The global model included the response variable Location (inside a constructed shelter or utilising natural protection versus outside) and fixed factors Outside wind speed, Outside temperature, Outside lux, Insect harassment, Shelter Temperature and Time of observation. No precipitation was observed during the study. The factor Species was included as a main effect and also as an interaction with environmental factors to examine the degree to which the shelter seeking behaviour of the two equid species differed. Potential interactions (with and without species) of environmental conditions were included. Subject nested within Social Group and then Farm was included in the models as a random factor.

In the case of insect harassment a model was constructed to determine the best measure (point count or harassment behaviours). Outside harassment behaviour was the best predictor and was 
included in the main analysis. Clipped or non-clipped was included in preliminary models as a factor but was found to not make a significant difference.

A GLMM was run with a null model and subsequently with the global model. This model was then 'pruned' by systematically removing factors with little or no predictive value until a final, best fit model was produced. Candidate models were assessed using the Akaike information criterion (AIC). To assess which environmental factors influenced equid use of outside protection such as shade, the same methods were used in a series of models for the response variable Outside Protection (use of protection versus outside in the sun). Only observations where outside protection would have been beneficial were included in the analysis; as such only animals outside, and observations made in sunny or windy weather were included. In order to investigate whether subjects experienced higher levels of insect harassment inside or outside the shelters, a repeated measures ANOVA was conducted comparing insect harassment behaviours in the same observation period.

\section{Results}

Equids were observed using some form of protection from the elements in $39 \%$ of observations. In $316 / 2735$ observations equids were using a constructed shelter and in 751/2735 observations equids were using natural protection. There were only 5 observations where a subject was showing potential signs of heat stress; two were donkeys (one showed signs in two separate observations) and two mules.

3.1 Effects of environmental conditions on constructed and natural shelter use: inside a shelter or using natural protection versus being outside.

Several environmental factors, and their interactions, had a significant influence on shelter use (Table 1.). Although there was no overall difference in the amount of shelter use by donkeys and mules, there were some significant differences between the species in the effects of specific environmental factors on SSB.

Table 1. Factors included in the best fit model of shelter use by donkeys and mules. Species comparisons use donkey as the reference category.

\begin{tabular}{|c|c|c|c|}
\hline Factor & & Z score & $P$ value \\
\hline Species & mule & -1.77 & 0.08 \\
\hline Outside temperature & & 2.08 & $0.04 *$ \\
\hline Lux & & 5.67 & $<0.0001^{*}$ \\
\hline Insect harassment behaviour & & -4.31 & $<0.0001^{*}$ \\
\hline Time of observation & & 1.01 & 0.31 \\
\hline
\end{tabular}




\begin{tabular}{|c|c|c|c|}
\hline Outside temperature*Species & mule & 2.98 & $0.003^{*}$ \\
\hline Insect harassment behaviour*Species & mule & 2.46 & $0.01 *$ \\
\hline $\begin{array}{l}\text { Outside temperature*Insect harassment } \\
\text { behaviour }\end{array}$ & & 0.71 & 0.48 \\
\hline Time of observation*Species & mule & 2.17 & $0.03 *$ \\
\hline $\begin{array}{l}\text { Species * Outside temperature* Insect harassment } \\
\text { behaviour }\end{array}$ & mule & -2.78 & $0.006 *$ \\
\hline
\end{tabular}

Outside temperature: During the study, the mean temperature was 26.4 degrees \pm 5.6 degrees, the minimum temperature recorded was 14.4 degrees and the maximum was 37 degrees. There was a significant main effect of outside temperature $(z=2.08, p=0.04)$, with shelter use increasing as the temperature rose. Mules and donkeys also reacted differently to rising temperatures, with mules being more affected by changes in temperature than donkeys (Outside temperature*Species: $z=$ $2.98, p=0.003$, Figure 2a).

a.

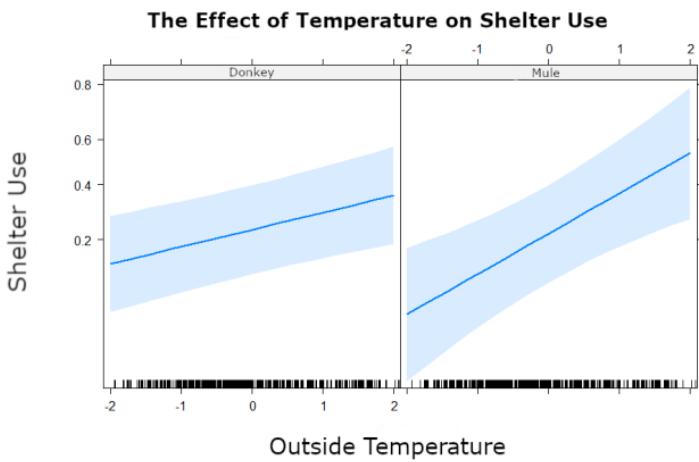

c.

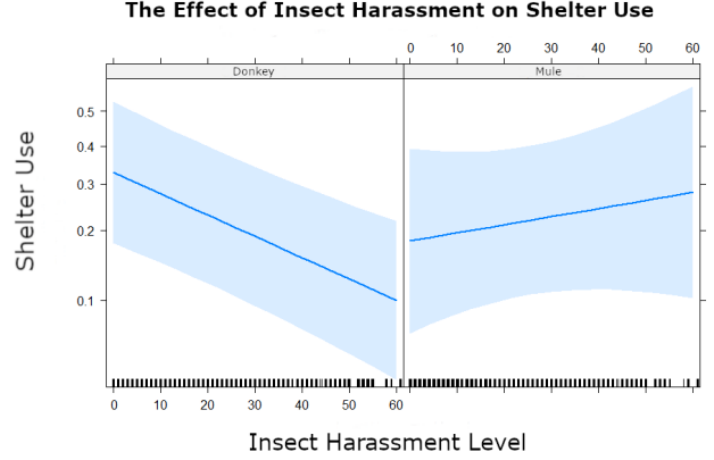

b.

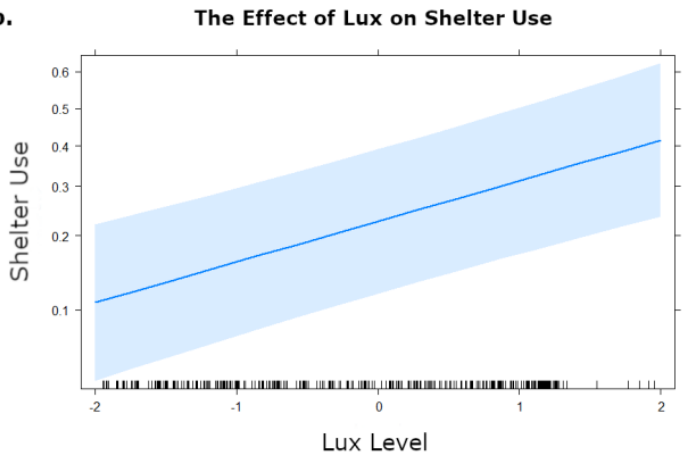

d. The Effect of Time of Day on Shelter Use

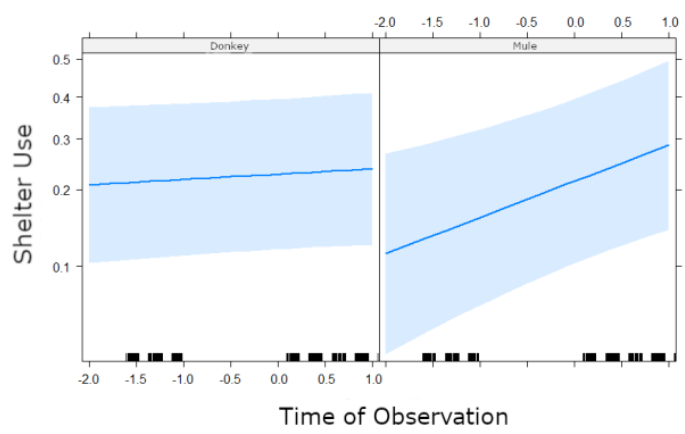

Fig. 2. The effect of environmental conditions on shelter use for donkeys and mules. Units are standardised for comparison within the model.

Lux: Mean lux recorded during the study was $60138.8 \pm 27489.3$, the minimum recorded was 3860 and the maximum was 112200. Lux was a strong predictor of shelter use in the model $(z=5.67, p$ $<0.0001$ ); across species, as lux levels rose, the number of equids using shelter increased (Figure $2 b$ ). 
Insect harassment behaviour: The mean number of insect harassment behaviours per minute was 23 \pm 15 behaviours, with a minimum of 0 and a maximum 63 behaviours. There was a significant difference in insect activity between shelters and outside spaces, with greater insect harassment inside shelters $(F(1,2)=51.37, p=.019)$. The main effect of insect harassment behaviour was also a strong predictor of shelter use $(z=-4.31, p=<0.0001)$. Overall, as insect harassment increased, shelter use decreased. There was a species specific difference in the effect of insect harassment on shelter seeking behaviour ( $z=2.46, p=0.01$ ), with mules using shelters slightly more at higher insect levels whereas donkeys showed a steep drop in shelter use at higher insect levels (Figure 2c). There was also a significant three-way interaction between insect harassment behaviour, outside temperature and species $(z=-2.78, p=0.006)$. Results suggest that, as temperatures increased, mules only showed an increase in shelter use if insect harassment was low, whereas donkeys showed an increase in shelter use as temperatures rose, regardless of insect harassment levels.

Time: All observations were made between $8 \mathrm{am}$ and $4 \mathrm{pm}$. There was no significant main effect of the time of observation on shelter use, however time of day did elicit a species specific difference ( $z$ $=2.17, p=0.03$ ). Mule shelter use rose throughout the day much more steeply than donkey shelter use, which rose only marginally (Figure $2 \mathrm{~d}$ ).

3.2 Effects of Environmental Conditions on the use of Outside Protection: utilising natural protection such as tree cover or shade versus being outside unprotected.

A number of environmental factors, and their interactions, had a significant influence on natural protection use (Table 2.). There were no significant differences in natural protection use by donkeys and mules.

Table 2. Factors included in the best fit model of outside protection use by donkeys and mules. Species comparisons use donkey as the reference category.

\begin{tabular}{|c|c|c|c|}
\hline Factor & & Z score & $P$ value \\
\hline Species & mule & -0.73 & 0.47 \\
\hline Wind speed & & 2.70 & $0.007^{*}$ \\
\hline Outside temperature & & 2.89 & $0.004 *$ \\
\hline Lux & & 1.42 & 0.16 \\
\hline Insect harassment & & -2.44 & $0.02 *$ \\
\hline \multicolumn{4}{|l|}{ behaviour } \\
\hline Time of observation & & 0.72 & 0.47 \\
\hline Lux*Species & mule & 1.76 & 0.08 \\
\hline
\end{tabular}




\begin{tabular}{|c|c|c|c|}
\hline $\begin{array}{l}\text { Time of } \\
\text { observation*Species }\end{array}$ & mule & 3.15 & $0.002^{*}$ \\
\hline $\begin{array}{l}\text { Wind speed*Outside } \\
\text { temperature }\end{array}$ & & 3.99 & $<0.0001 *$ \\
\hline
\end{tabular}

Outside temperature: Outside protection use significantly increased at higher temperatures $(z=$ $2.89, p=0.004)$.

Lux: Although the lux*species interaction only approached significance $(z=1.84, p=0.08)$, this factor was retained in the best fit model. Donkeys showed a pattern of slightly increased outside protection use at high lux levels, for mules this increase was much steeper (Figure 3a).

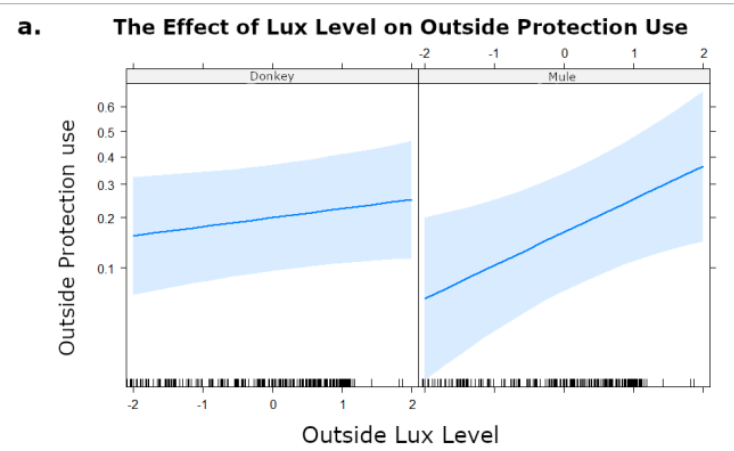

c. The Effect of Insect Harassment on Outside Protection Use

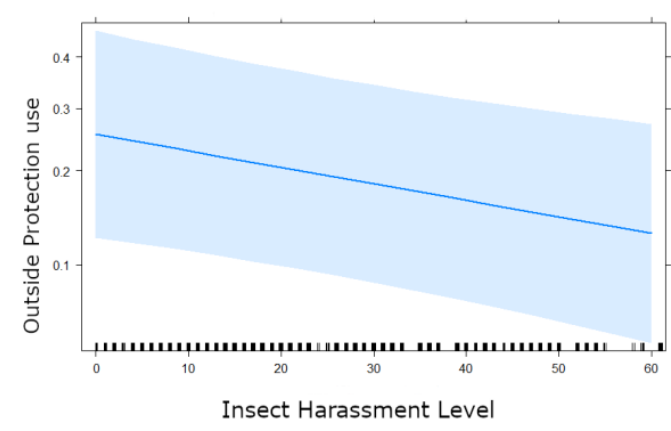

b. Wind Speed*Temperature Interaction in Outside Protection Use

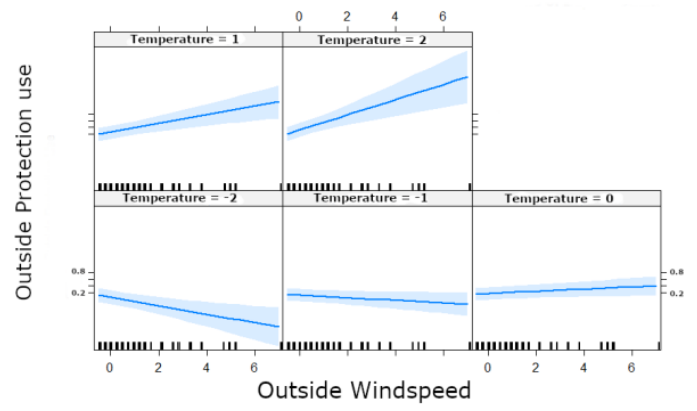

d.

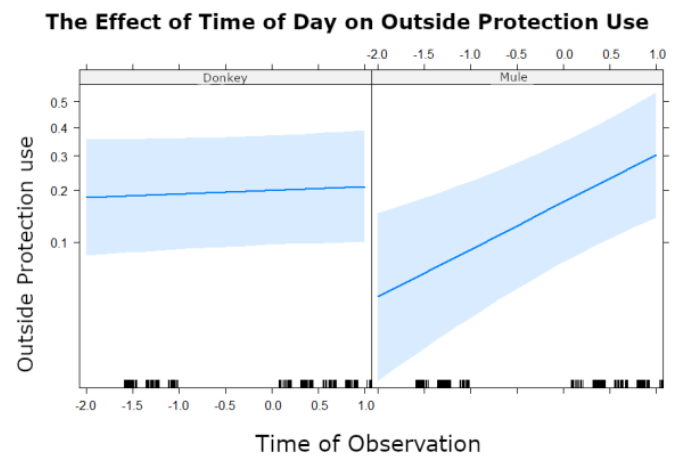

Fig.3. The effect of environmental conditions on outside protection use for donkeys and mules. Units are standardised for comparison within the model.

Wind: Across species, as wind speeds increased, outside protection use also increased $(z=2.70, p=$ $0.007)$. The interaction of wind speed and temperature was the strongest predictor of outside protection use; as temperatures and wind speed increased, outside protection use also increased, however at low temperatures outside protection use decreased or remained stable as wind speeds increased ( $z=3.99, p<0.0001$; Figure $3 b)$. 
Insect harassment: Across species, as the level of insect harassment increased equid outside protection use decreased $(z=-2.44, p=0.02$; Figure $3 c)$.

Time: The interaction of time*species was significant $(z=3.15, p=0.002)$, with protection use by donkeys showing a marginal increase over the day and mules showing a much steeper increase over time (Figure 3d).

\section{Discussion}

In this study, overall protection use was 39\%, which falls within figures for protection use by horses in comparable climates of 50 and 25\% (Holcomb et al., 2014; Holcomb and Stull, 2016). Although constructed shelter use was generally quite low compared to outside protection use, both species increased their shelter use as temperatures rose. This result is in accordance with the findings from horses that shade use is highest on sunniest days (Holcomb and Stull, 2016), and that they prefer artificial shelters over natural shelter during the summer and at temperatures above $20^{\circ} \mathrm{C}$ (Hartmann et al., 2015; Snoeks et al., 2015). Despite previous research with working donkeys showing heat stress in donkeys at temperatures above $30^{\circ} \mathrm{C}$ (Ayo et al., 2008), only 2 donkeys in this study showed potential signs of heat stress. This highlights the need for clear measures of the effects of environmental factors on healthy equids and suggests that working equids, who are under physical strain and are often in poor condition, may often have a lowered UCT and be more susceptible to hyperthermia (Burn et al., 2010b). Future research should assess physiological measures of heat stress, establishing the TNZ of healthy donkeys and mules. Interestingly, lux was a stronger predictor of constructed shelter use than temperature, this is in line with previous research that has shown that SSB in horses more closely follows patterns of solar radiation levels than ambient temperature (Holcomb et al., 2014). It is unsurprising that lux specifically influences patterns of constructed shelter use, as a building provides a more effective refuge from solar radiation than natural protection alone.

The particular sensitivity of mules to fluctuations in temperature and lux may be due to the geographically different evolution of horses and donkeys, and their adaptations to different climates (Bignon and Eisenmann, 2002). Donkeys are better adapted to arid, hot climates and hence intense sunlight levels (Burden and Thiemann, 2015). In contrast, horses are more adapted to cold conditions (Autio et al., 2007), with certain breeds showing specific adaptations to cold conditions, such as a hypometabolism (Autio et al., 2006; Brinkmann et al., 2012). As a hybrid, mules often display attributes that are intermediate between the parental species, such as their winter hair coat growth (Osthaus et al., 2017). Thus, it may be expected that they are less adapted to conditions such as high temperatures and lux levels than donkeys, as was found in this study. However, the average age of mules sampled in the study was higher than the average donkey age, potentially leading to a reduction in the ability to thermoregulate and an increase in the need for shelter provision in the mule subjects (Holcomb, 2017; McKeever et al., 2010). Individual differences such as those relating 
to body size, nutritional state and coat colour also have the potential to affect an equids ability to thermoregulate and future research could profitably explore these effects (Autio et al., 2007; Cappai et al., 2017; Holcomb, 2017).

In both our models, insect harassment was a significant predictor of decreasing shelter use. This pattern was also seen in the use of outside protection, suggesting that the vegetation providing shade cover may have been supporting a larger number of insects in comparison to open areas. These differences in harassment levels provide an explanation for the contradictory findings of related studies with horses, where in some cases, shelter and natural protection use was found to increase with increased insect harassment, and in others it was found to decrease (Hartmann et al., 2015; Holcomb et al., 2014, 2013; King and Gurnell, 2010; Rubenstein and Hohmann, 1989; Snoeks et al., 2015). In studies of shelter seeking behaviour, it is therefore imperative to not only record the environmental conditions outside, but also inside available shelters and natural protection areas. Mules showed an increase in shelter use at high temperatures but only at low levels of insect harassment, suggesting that high levels of insect harassment deterred mules from seeking shelter, even under circumstances in which they would normally use a shelter. For donkeys, insect harassment appeared to be less of a driver of shelter seeking behaviour, an observation also found when comparing the SSB of donkeys and horses in a temperate climate (Proops et al., 2019). The reason for mules being more affected by insect harassment than donkeys is unknown. It is possible that they are more sensitive to insect bites, it has been reported that mules have died from outbreaks of buffalo gnats in the US, whereas cattle and horses have experienced a loss of body condition but fatalities in these species were not mentioned (Bishopp, 1942). It is possible that the evolution of donkeys in hot climates where there are naturally higher numbers of insects has resulted in increased insect tolerance in comparison to mules. A direct comparison between donkeys, mules and horses would be useful to further investigate this apparent difference.

Insect harassment behaviours were a better fit in the models than fly count as a proxy of insect harassment. This supports the finding of Proops et al. (2019) and Powell et al. (2006) that 'comfort movements' (referred to in this paper as insect harassment behaviours) are a reliable proxy for the number of insects on the equid. This is relevant as in the field, insect harassment behaviours are easier to count from a distance without disturbing the natural behavioural patterns of the study equids. Insect harassment behaviours also take into account harassment from insects that are too small to see from afar such as midges. Insect harassment behaviours are equally easy to see in equids with dark and light coats whereas counting fly numbers on dark coated equids is much more difficult. Measuring insect harassment behaviours also represents how aggravated the equids are by the insects, for example some insects may be more numerous but less of an annoyance than another insect species.

Previous research into the SSB of horses indicates that SSB is affected by combinations of wind speed and temperature, with increases in wind speed leading to increases in SSB in colder weather (Heleski and Murtazashvili, 2010; Mejdell and Bøe, 2005). In hotter weather, both shade and high 
winds provide relief from uncomfortably high temperatures, and so SSB will reflect a trade-off between the use of shade and access to windy areas. Perhaps surprisingly, in our study, wind speed was not a significant predictor of shelter use. However, throughout this study, the maximum recorded wind speed was only $3.2 \mathrm{~m} / \mathrm{s}$ and so may not have been high enough to significantly affect SSB. Wind speed did seem to play a more important role in outside protection use, potentially because when equids are outside they are more exposed to the effects of wind and its interactions with other environmental factors. In this study, increased outside protection use was seen when there were higher wind speeds and high temperatures. This suggests that standing in the wind alone was not enough to dissipate excess heat in high temperatures, and that subjects sought shade (that did not block the wind) to increase the amount of heat lost through convection. At lower temperatures (within the TNZ of horses), wind speed did not appear to influence outside protection use, perhaps because the equids did not have to adjust their behaviour to lose excess heat. At low wind speeds, there may be less benefit from staying outside in comparison to sheltering inside a building. Typically, SSB is also affected by the interaction of wind speed with temperature and precipitation (Heleski and Murtazashvili, 2010; Mejdell and Bøe, 2005), however no observations in this study included precipitation. Despite being commonly found in climates with extreme wet seasons (Burn et al., 2010b), donkeys appear more adapted to semi-arid climates, and readily seek shelter in cold, wet weather (Proops et al., 2019). It would therefore be of interest to explore the SSB of healthy donkeys and mules in hot, wet i.e. tropical climates.

Finally, outside protection use for both species also increased with time, being highest at the end of the observation period (between $2 \mathrm{pm}$ and $4 \mathrm{pm}$ ). This finding is in accordance with Holcomb et al. (2014) who demonstrated that horses with an availability of shade did not use it during the hottest part of the day, which in this study occurred between $11 \mathrm{am}$ and $3 \mathrm{pm}$. Time of day also affects whether shade from natural protection is even available and where it will fall. Temporal patterns were similar in both outside protection and shelter use models suggesting that time of day has a similar effect on both shelter and shade seeking, with both being used increasingly throughout the day, although significantly more by mules than by donkeys.

\section{Conclusion}

Shelter was most readily sought during periods of high temperatures and lux levels. Mules were more affected by changes in temperature, lux and insect harassment compared to donkeys. Use of protection from the elements was relatively high (39\%) across the study, suggesting that the provision of shelter to equids in this climate confers a welfare advantage. Establishing the natural shelter seeking behaviour of healthy donkeys and mules across climates can help to inform welfare guidelines and management of these animals. 
Declaration of Interests: No competing interests have been declared.

Ethical Animal Research: This research was approved by the University of Southampton's Animal Welfare Ethics Research Board and adhered to the EU Directive 2019/63/EU for animal experiments and the Association of Animal Behaviour guidelines for the treatment of animals. The study did not affect the management practices and decisions made by the equid owners. Any subjects that ceased to meet the inclusion criteria of the study (free access to an outside area and a constructed shelter, no rug or clipping and in good health) were excluded from further observations. The Donkey Sanctuary gave informed consent for their animals' inclusion in the study.

Funding: The study was funded by an ESRC South Coast Doctoral Training Partnership bursary awarded to EH and a Donkey Sanctuary research grant for overseas fieldwork awarded to EH and LP.

Authorship Statement: The idea for the paper was conceived by LP, FB, EH. The experiments were designed by LP, FB, EH. The data was collected by EH. The data were analysed by EH, LP. The paper was written by EH, LP, FB.

Acknowledgements: We are grateful to the staff at El Refugio del Burrito and The Donkey Sanctuary, for their willingness to facilitate this research. 


\section{References}

Agencia Estatal de Meteorologia, Instituto de Meteorologia Portugal, G. de E., 2011. Iberian Climate Atlas. AEMET documentation Unit, Spain.

Autio, E., Heiskanen, M.-L., Mononen, J., 2007. Thermographic Evaluation of the Lower Critical Temperature in Weanling Horses. J. Appl. Anim. Welf. Sci. 10, 207-216. https://doi.org/10.1080/10888700701353493

Autio, E., Neste, R., Airaksinen, S., Heiskanen, M.-L., 2006. Measuring the Heat Loss in Horses in Different Seasons by Infrared Thermography. J. Appl. Anim. Welf. Sci. 9, 211-221. https://doi.org/10.1207/s15327604jaws0903

Ayo, J.O., Dzenda, T., Olaifa, F., Ake, S.A., Sani, I., 2014. Diurnal and seasonal fluctuations in rectal temperature, respiration and heart rate of pack donkeys in a tropical Savannah Zone. J. Equine Sci. 25, 1-6. https://doi.org/10.1294/jes.25.1

Ayo, J.O., Dzenda, T., Zakari, F.O., 2008. Individual and Diurnal Variations in Rectal Temperature, Respiration, and Heart Rate of Pack Donkeys during the Early Rainy Season. J. Equine Vet. Sci. 28, 281-288. https://doi.org/10.1016/j.jevs.2008.03.003

Bignon. O. Eisenmann, V., 2002. Western European Late Glacial horse diversity and its ecological implications., Equids in. ed. 9th ICAZ Conference, Durham.

Bishopp, F.C., 1942. Yearbook of Agriculture Some Insect Pests of Horses and Mules.

Brinkmann, L., Gerken, M., Riek, A., 2012. Adaptation strategies to seasonal changes in environmental conditions of a domesticated horse breed, the Shetland pony (Equus ferus caballus). J. Exp. Biol. 215, 1061-1068. https://doi.org/10.1242/jeb.064832

Burden, F., Thiemann, A., 2015. Donkeys Are Different. https://doi.org/10.1016/j.jevs.2015.03.005

Burn, C.C., Dennison, T.L., Whay, H.R., 2010a. Relationships between behaviour and health in working horses, donkeys, and mules in developing countries. Appl. Anim. Behav. Sci. 126, 109118. https://doi.org/10.1016/j.applanim.2010.06.007

Burn, C.C., Dennison, T.L., Whay, H.R., 2010b. Environmental and demographic risk factors for poor welfare in working horses, donkeys and mules in developing countries. Vet. J. 186, 385-392. https://doi.org/10.1016/j.tvjl.2009.09.016

Cappai, M.G., Lunesu, M.G.A., Accioni, F., Liscia, M., Pusceddu, M., Burrai, L., Nieddu, M., Dimauro, C., Boatto, G., Pinna, W., 2017. Blood serum retinol levels in Asinara white donkeys reflect albinism-induced metabolic adaptation to photoperiod at Mediterranean latitudes. Ecol. Evol. 7, 390-398. https://doi.org/10.1002/ece3.2613

Curtis, S.E., 1983. Environmental management in animal agriculture. lowa State University Press.

Cymbaluk NF, C.G., 1990. Environmental effects on thermoregulation and nutrition of horses. Vet. Clin. North Am. Equine Pract. 6, 355-372. 
Dey, S., Dwivedi, S.K., Malik, P., Panisup, A.S., Tandon, S.N., Singh, B.K., 2010. Mortality associated with heat stress in donkeys in India. Vet. Rec. 166, 143-144. https://doi.org/10.1136/vr.c504

Hartmann, E., Hopkins, R.J., von Brömssen, C., Dahlborn, K., 2015. Daytime shelter use of individually kept horses during Swedish summer. Acta Vet. Scand. 57. https://doi.org/10.2527/jas.20148598

Heleski, C.R., Murtazashvili, I., 2010. Daytime shelter-seeking behavior in domestic horses. J. Vet. Behav. Clin. Appl. Res. 5, 276-282. https://doi.org/10.1016/j.jveb.2010.01.003

Holcomb, K.E., 2017. Is shade for horses a comfort resource or a minimum requirement? J. Anim. Sci. 95, 4206-4212. https://doi.org/10.2527/jas.2017.1641

Holcomb, K.E., Stull, C.L., 2016. Effect of time and weather on preference, Frequency, and duration of shade use by horses. J. Anim. Sci. 94, 1653-1661. https://doi.org/10.2527/jas.2015-0160

Holcomb, K.E., Tucker, C.B., Stull, C.L., 2014. Preference of domestic horses for shade in a hot, sunny environment. J. Anim. Sci. 92, 1708-1717. https://doi.org/10.2527/jas2013-7386

Holcomb, K.E., Tucker, C.B., Stull, C.L., 2013. Physiological, behavioral, and serological responses of horses to shaded or unshaded pens in a hot, sunny environment. J. Anim. Sci. 91, 5926-5936. https://doi.org/10.2527/jas.2013-6497

Honstein, R.N. Monty, J.D., 1977. Physiologic responses of the horse to a hot, arid environment. Am. J. Vet. Res. 38, 1041-1043.

Keiper, R.R., Berger, J., 1982. Refuge-Seeking and Pest Avoidance by Feral Horses in Desert and Island Environments. Appl. Anim. Ethol. 9, 111-120.

King, S.R.B., Gurnell, J., 2010. Effects of fly disturbance on the behaviour of a population of reintroduced Przewalski horses (Equus ferus przewalskii) in Mongolia. Appl. Anim. Behav. Sci. 125, 22-29. https://doi.org/10.1016/j.applanim.2010.03.006

Kottek, M., Grieser, J., Beck, C., Rudolf, B., Rubel, F., 2006. World Map of the Koppen-Geiger climate classification updated. Meteorol. Zeitschrift 15, 259-263. https://doi.org/10.1127/09412948/2006/0130

McKeever, K.H., Eaton, T.L., Geiser, S., Kearns, C.F., Lehnhard, R.A., 2010. Age related decreases in thermoregulation and cardiovascular function in horses. Equine Vet. J. 42, 220-227. https://doi.org/10.1111/j.2042-3306.2010.00259.x

Mejdell, C.M., Bøe, K.E., 2005. Responses to climatic variables of horses housed outdoors under Nordic winter conditions. Can. J. Anim. Sci. 85, 307-308. https://doi.org/10.4141/A04-066

Minka, N.S., Ayo, J.O., 2007. Effects of Shade Provision on Some Physiological Parameters, Behavior and Performance of Pack Donkeys (Equinus asinus) during the Hot-Dry Season. J. Equine Sci 18, 39-46. https://doi.org/10.1294/jes.18.39

Morgan, K., 1998. Thermoneutral Zone and Critical Temperatures of Horses. J. Therm. Biol. 23, 5961. 
Morgan, K., Ehrlemark, A., Sällvik, K., 1997. Dissipation of heat from standing horses exposed to ambient temperatures between $-3^{\circ} \mathrm{C}$ and $37^{\circ} \mathrm{C}$. J. Therm. Biol. 22, 177-186.

https://doi.org/10.1016/\$0306-4565(97)00007-7

Osthaus, B., Proops, L., Long, S., Bell, N., Hayday, K., Burden, F., 2017. Hair coat properties of donkeys, mules and horses in a temperate climate. Equine Vet. J. 0, 1-4.

https://doi.org/10.1111/evj.12775

Powell, D.M., Danze, D.E., Gwinn, M.A., 2006. Predictors of biting fly harassment and its impact on habitat use by feral horses (Equus caballus) on a barrier island. J. Ethol. 24, 147-153. https://doi.org/10.1007/s10164-005-0174-2

Pritchard, J.C., Barr, A.R.S., Whay, H.R., 2006. Validity of a behavioural measure of heat stress and a skin tent test for dehydration in working horses and donkeys. Equine Vet. J. 38, 433-438. https://doi.org/10.2746/042516406778400646

Pritchard, J.C., Burn, C.C., Barr, A.R.S., Whay, H.R., 2008. Validity of indicators of dehydration in working horses: A longitudinal study of changes in skin tent duration, mucous membrane dryness and drinking behaviour. Equine Vet. J. 40, 558-564.

https://doi.org/10.2746/042516408X297462

Proops, L., Osthaus, B., Bell, N., Long, S., Hayday, K., Burden, F., 2019. Shelter seeking behaviour of donkeys and horses in a temperate climate. J. Vet. Behav. 32, 16-23.

https://doi.org/10.1016/J.JVEB.2019.03.008

Rubenstein, D.I., Hohmann, M.E., 1989. Parasites and Social Behavior of Island Feral Horses. Oikos 55, 312-320. https://doi.org/10.2307/3565589

Silanikove, N., 2000. Effects of heat stress on the welfare of extensively managed domestic ruminants. Livest. Prod. Sci. 67, 1-18. https://doi.org/10.1016/S0301-6226(00)00162-7

Snoeks, M.G., Moons, C.P.H., Ödberg, F.O., Aviron, M., Geers, R., 2015. Behavior of horses on pasture in relation to weather and shelter-A field study in a temperate climate. J. Vet. Behav. Clin. Appl. Res. 10, 561-568. https://doi.org/10.1016/j.jveb.2015.07.037

Swann, W.J., 2006. Improving the welfare of working equine animals in developing countries. Appl. Anim. Behav. Sci. 100, 148-151. https://doi.org/10.1016/j.applanim.2006.04.001

Team, Rs., 2015. RStudio: Integrated Development for R.

Zakari, F.O., Ayo, J.O., Rekwot, P.I., Kawu, M.U., Minka, N.S., Olaifa, F.H., Ibrahim, M.J., Avazi, D.O., 2018. Daily rhythmicity of behavioral responses in donkeys of different age groups during the cold-dry (harmattan) and hot-dry seasons in a tropical savannah. J. Vet. Behav. 28, 46-53. https://doi.org/10.1016/j.jveb.2018.08.001 